\title{
Effects of Diaphragmatic Breathing With and Without Pursed-Lips Breathing in Subjects With COPD
}

\author{
Liliane PS Mendes, Karoline S Moraes, Mariana Hoffman, Danielle SR Vieira, \\ Giane A Ribeiro-Samora, Susan M Lage, Raquel R Britto, and Verônica F Parreira
}

\begin{abstract}
BACKGROUND: Breathing exercises, such as diaphragmatic breathing and pursed-lips breathing, play a role in some individuals with COPD and might be considered for those patients who are unable to exercise. However, in the literature are reports of some adverse effects of diaphragmatic breathing in patients with COPD. Thus, the purpose of this study was to assess the effects of diaphragmatic breathing and diaphragmatic breathing combined with pursed-lips on chest wall kinematics, breathlessness, and chest wall asynchrony in subjects with COPD, and also to assess whether the combination of both exercises reduces the adverse effects of diaphragmatic breathing while maintaining its benefits. METHODS: Seventeen subjects with COPD, mean \pm SD, $65 \pm 7$ y of age, with a history of smoking and clinical stability without hospitalization or symptoms of exacerbation in the past $4 \mathrm{wk}$, were evaluated. On day 1 , participants' characteristics were collected, and they learned diaphragmatic breathing and its combination with pursed-lips breathing. On day 2 , the participants were evaluated by optoelectronic plethysmography with the participants in the seated position while performing breathing exercises. RESULTS: Diaphragmatic breathing and diaphragmatic breathing plus pursedlips breathing promoted a significant increase in chest wall tidal volume and its compartments as well as a reduction in breathing frequency compared with quiet breathing. No significant changes were observed in dyspnea or end-expiratory volume of the chest wall. A significant increase in asynchrony (inspiratory-expiratory phase ratio) was observed during diaphragmatic breathing and diaphragmatic breathing plus pursed-lips breathing compared with quiet breathing, with no differences observed between the exercises. CONCLUSIONS: Despite the increase in asynchrony, both breathing exercises were able to improve chest wall volumes without affecting dyspnea. The combination of exercises maintained the benefits but did not reduce the adverse effects of diaphragmatic breathing. Key words: COPD; diaphragmatic breathing; pursed-lips; optoelectronic plethysmography; breathing pattern; chest wall motion; asynchrony. [Respir Care 2019;64(2):136-144. (c) 2019 Daedalus Enterprises]
\end{abstract}

\section{Introduction}

COPD is a treatable disease characterized by chronic air-flow limitation and persistent symptoms, such as dyspnea, cough, weight loss, and fatigue. ${ }^{1} \mathrm{COPD}$, as a leading cause of morbidity, is an important public health concern, and clinical exacerbations are responsible for recurrent hospitalizations and an increase in the related economic health-care costs. ${ }^{1,2}$ Pulmonary rehabilitation is a key

\footnotetext{
Ms Mendes, Ms Moraes, Dr Hoffman, Dr. Ribeiro-Samora, and Dr Lage are affiliatted with Rehabilitation Sciences Program, Universidade Federal de Minas Gerais, Belo Horizonte, Minas Gerais, Brazil. Dr Vieira is affiliated with Health Science Department, Universidade Federal de Santa Catarina, Araranguá, Santa Catarina, Brazil. Drs Britto and Parreira are affiliated with Department of Physiotherapy, Universidade Federal de Minas Gerais, Belo Horizonte, Minas Gerais, Brazil .
}

Financial support was provided by Coordenação de Aperfeiçoamento de Pessoal de Nível Superior, Fundação de Amparo a Pesquisa de Minas Gerais, and Conselho Nacional de Desenvolvimento Científico e Tecnológico.

Dr Parreira presented a version of this paper at the European Respiratory Society Annual Congress, September 21, 2010, in Barcelona, Spain, and 


\section{Diaphragmatic and PuRsed-Lips Breathing}

component of managing COPD and involves exercise training, education and self-management interventions, encouraging behavioral change, and stimulus to physical activity. ${ }^{3}$ Pulmonary rehabilitation has been shown to improve symptoms, exercise tolerance, and health-related quality of life as well as reduce hospitalizations. ${ }^{2-4}$ Breathing exercises, such as diaphragmatic breathing and pursed-lips breathing, which can be performed separately or in combination, ${ }^{5-9}$ have a role in managing breathlessness in patients with COPD and can also be considered for those who are unable to undertake exercise training. ${ }^{1,7}$ These techniques aim to reduce dyspnea, improve ventilation and gas exchange, optimize chest wall motion, and reduce hyperinflation. ${ }^{7,10,11}$

Diaphragmatic breathing consists of a smooth and deep nasal inspiration with anterior displacement of the abdominal region, which emphasizes the action of the diaphragm..$^{6,10,12}$ For patients with COPD, the immediate benefits of diaphragmatic breathing are an increase in the tidal volume and oxygen saturation, reduction in breathing frequency, and improvements in ventilation and hematosis. ${ }^{12,13}$ Adverse effects include an increase in the asynchronous and paradoxical movement of the chest wall as well as increased work of breathing and dyspnea in the subjects with the most severe conditions. ${ }^{6,10,12}$

Pursed-lips breathing consists of a soft exhalation performed for 4 to $6 \mathrm{~s}$ against the resistance of partially closed lips and clenched teeth.6,10,14 It is frequently adopted spontaneously and voluntarily by some subjects with COPD to control and relieve dyspnea and can be performed at rest or during exercise. ${ }^{14-16}$ Several studies have shown that the benefits of pursed-lips breathing in subjects with COPD include decreased breathing frequency and lung hyperinflation, improvements in the $\mathrm{P}_{\mathrm{CO}_{2}}$ and oxygen in the blood, and increased tidal volume and oxygen saturation. $6,10,14,17$ However, dyspnea relief remains poorly consistent, because this response is different among subjects. ${ }^{6,10}$

With regard to the combination of these techniques (diaphragmatic breathing plus pursed-lips breathing) in

at American Thoracic Society International Conference, May 17, 2014, in San Diego, California.

The authors have disclosed no conflicts of interest.

Correspondence: Verônica Franco Parreira, Department of Physiotherapy, Universidade Federal de Minas Gerais, Avenida Antônio Carlos, 6627, Pampulha, 31270-901 Belo Horizonte, MG Brazil. E-mail: veronicaparreira@yahoo.com.br.

DOI: $10.4187 /$ respcare.06319

\section{QUICK LOOK}

\section{Current knowledge}

Breathing exercises, such as diaphragmatic breathing and pursed-lips breathing, play a role in some individuals with COPD and might be considered for symptom management and for those patients unable to exercise. Both exercises present benefits for patients with COPD; however, there are reports of some adverse effects of diaphragmatic breathing.

\section{What this paper contributes to our knowledge}

We found that diaphragmatic breathing with and without pursed-lips breathing improved chest wall volumes and oxygenation, reduced breathing frequency, and provided more volume for hematosis without increasing dyspnea. The addition of pursed-lips breathing to diaphragmatic breathing provided greater changes in breathing parameters, especially in relation to time variables. Therefore, our work supports the positive acute effects of these breathing exercises for patients with COPD.

subjects with COPD, Jones et $\mathrm{al}^{5}$ reported a significant decrease in breathing frequency and oxygen consumption during the combined exercise compared with the spontaneous breathing. The breathing frequency was significantly lower during diaphragmatic breathing plus pursed-lips breathing, even in relation to each technique in isolation, although there was no difference in oxygen consumption among the 3 exercises. $^{5}$ According to these findings, a combination of these techniques seemed to be more effective than performing the exercises separately. However, to the best of our knowledge, this was the only study to evaluate the effects of the combination of the techniques for only these 2 outcomes. Thus, the questions addressed in this study were the following: What are the effects of diaphragmatic breathing plus pursed-lips breathing on chest wall motion, breathing pattern, dyspnea, and chest wall asynchrony in subjects with COPD? Could the combination reduce the adverse effects of diaphragmatic breathing while maintaining its benefits?

\section{Methods}

\section{Participants}

This was a quasi-experimental study, developed in an university research laboratory with participants who met the following inclusion criteria: diagnosis of COPD confirmed by pulmonary function test, ${ }^{1}$ history of smoking, 
between 45 and $75 \mathrm{y}$ of age, clinically stable (no exacerbations and/or hospitalization in the past 4 weeks), ${ }^{13,14,17}$ no report of neurological or psychiatric disorders, body mass index between 18.5 and $29.99 \mathrm{~kg} / \mathrm{m}^{2},{ }^{18}$ and no previous participation in a pulmonary rehabilitation program. Subjects were excluded if they presented with other pulmonary diseases or were unable to understand and/or perform any procedure of the study. Two investigators (KSM and SML) were previously trained to carry out data collection, and the instructions given to the participants were performed by one of them (KSM). This study was approved by the ethics committee of the institution (ETIC 577/08), and all the participants signed a written consent form. The study was performed at Universidade Federal de Minas Gerais, Belo Horizonte, Brazil.

\section{Intervention}

Data were collected over $2 \mathrm{~d}$, with a maximum interval of 1 week between them. Initially, clinical and demographic data were collected. Then, the Medical Research Council dyspnea scale was used to assess symptoms. ${ }^{19}$ Next, maximum respiratory pressures were assessed by using a manovacuometer (Ger-Ar, São Paulo, Brazil) according to recommendations. ${ }^{20}$ The participants then performed the pulmonary function test (Vitalograph 2120, Vitalograph, Buckingham, United Kingdom). ${ }^{21}$ After that, the participants learned how to perform diaphragmatic breathing and the diaphragmatic breathing plus pursed-lips breathing.

For diaphragmatic breathing, they were instructed to perform a nasal inspiration moving predominantly the abdomen, reducing the movement of the rib cage.6,22 For diaphragmatic breathing plus pursed-lips breathing, they were instructed to perform a diaphragmatic breathing, and then, exhale the air with lips partially closed. ${ }^{14,23}$ Initially, tactile stimulus was used by positioning one of the participant's hands on his or her abdomen, at the level of the umbilicus, while placing the other hand on the chest, in the sternal notch region, to allow comparison of ventilation between both locations. ${ }^{12}$ Moreover, during the learning period, 2 bands from the respiratory inductive plethysmography (Respitrace, NIMS, Miami, Florida) were placed, one on the rib cage and the other on the abdomen, ${ }^{24}$ and the participants were positioned in front of a computer screen to follow the movements of the chest wall for a visual feedback. In addition, standard verbal instruction was given to ensure correct technique performance.

On the second day, the participants were initially reminded about exercise performance. They were then evaluated by using optoelectronic plethysmography, which is a valid and reliable system ${ }^{25,26}$ composed of cameras (6 in this study) that register movement of the chest wall through 89 markers placed on the trunk. Technical details, including marker positions and calibration processes of the op- toelectronic plethysmography system, have been published. ${ }^{27}$ To enable the cameras to better capture the images, the participants were seated with their arms slightly externally rotated. Then, 3 different conditions were registered: (1) 6 min of quiet breathing ( 3 sets of 2 min each), defined as participants' spontaneous breathing pattern; (2) $6 \mathrm{~min}$ of diaphragmatic breathing ( 3 sets of 2 min each); and (3) 6 min of diaphragmatic breathing plus pursed-lips breathing ( 3 sets of 2 min each).

The exercises were performed in a random order. The dyspnea rating was recorded before and immediately after each condition (quiet breathing, diaphragmatic breathing, and diaphragmatic breathing plus pursed-lips breathing) by using the modified Borg scale $(0-10$ points, with 0 , no dyspnea; and 10, maximum dyspnea). ${ }^{28}$ Oxygen saturation and heart rate were continuously assessed during data collection by using a pulse oximeter (Datex TuffSat Oximeter, GE Healthcare, Helsinki, Finland). A minimum interval of 10 min between the conditions was given to allow the return of clinical parameters (heart rate, breathing frequency, and dyspnea) to baseline values. The same researcher (KSM) provided instructions on how to perform the breathing exercises on the first and second days. In addition, participants received standard verbal instruction at the beginning of each series of exercises and were monitored during data collection to ensure that they were performing the exercises correctly.

\section{Outcome Variables}

The breathing pattern variables analyzed were chest wall tidal volume, end-inspiratory chest wall volume, end-inspiratory rib-cage volume, end-inspiratory abdomen volume, end-expiratory chest wall volume, end-expiratory rib-cage volume, end-expiratory abdomen volume, minute ventilation, breathing frequency, inspiratory time, expiratory time, and duty cycle. The chest wall motion variables analyzed were pulmonary rib-cage percentage contribution, abdominal rib-cage percentage contribution, and abdomen percentage contribution. The asynchrony between chest wall compartments [rib cage (pulmonary rib cage + abdominal rib cage) $\times$ abdomen and pulmonary rib cage $X$ abdominal rib cage] was calculated by using the software MatLab (MathWorks, Natick, Massachusetts) by using the following variables: the phase angle that reflects the delay between the excursions of the compared compartments, ${ }^{29}$ the inspiratory phase ratio, and the expiratory phase ratio that expresses the percentage of time in which the compartments move in opposite directions during the inspiration and during expiration, respectively. ${ }^{24,30}$ Perception of dyspnea was assessed by using the modified Borg scale. ${ }^{28}$ 


\section{Sample Size Calculation}

Sample size calculation was determined after a pilot study with the first 10 participants. The following variables were considered: chest wall tidal volume, breathing frequency, inspiratory phase ratio, and expiratory phase ratio. When considering a large effect size $(f>0.40)$ for each variable, a power of 0.80 , and an alpha error probability of $5 \%$, the estimated sample size was 15 subjects.

\section{Data Reduction}

The intermediate minute from each of the 3 series registered was used to determine the breathing pattern, chest wall motion, and chest wall asynchrony variables of quiet breathing and also of the breathing exercises. Thus, all breathing cycles between 30 and $90 \mathrm{~s}$ of each series of 2 min were used for all the conditions evaluated.

\section{Statistical Analysis}

Data are presented as measures of central tendency and dispersion, and the normality was verified by using the Shapiro-Wilk test. To compare quiet breathing, diaphragmatic breathing, and diaphragmatic breathing plus pursedlips breathing, repeated-measures analysis of variance or the Friedman test was used. Post hoc analyses were performed by using Bonferroni or Wilcoxon tests according to data distribution. For dyspnea comparisons, the chi-square test was used. The level of significance was set at 5\%. The Statistical Package for the Social Sciences, version 17.0 (SPSS, Chicago, Illinois) was used for analyses.

\section{Results}

Initially, 18 participants with COPD were selected to participate in the study; 1 participant was excluded from data analysis due to irregularities on data recording. The demographic, anthropometric, and clinical characteristics of the participants are shown in Table 1. The sample was composed of subjects with moderate-to-severe COPD. The breathing pattern data during quiet breathing, diaphragmatic breathing, and diaphragmatic breathing plus pursedlips breathing are presented in Table 2. Both breathing exercises (diaphragmatic breathing and diaphragmatic breathing plus pursed-lips breathing) promoted significant increases in chest wall tidal volume and end-inspiratory volume of the chest wall and its compartments compared with quiet breathing.

A significant decrease in the breathing frequency and a significant increase in inspiratory time and expiratory time were observed for diaphragmatic breathing and diaphragmatic breathing plus pursed-lips breathing when compared
Table 1. Characteristics of the Participants

\begin{tabular}{lc}
\hline \hline \multicolumn{1}{c}{ Characteristics } & Value \\
\hline Male sex, $\%$ & 88 \\
Age, mean \pm SD y & $65 \pm 7$ \\
BMI, mean \pm SD kg/m ${ }^{2}$ & $23.0 \pm 2.5$ \\
Smoking history, mean \pm SD packs/y & $57.8 \pm 33.6$ \\
$\mathrm{FEV}_{1}$, mean $\pm \mathrm{SD} \%$ predicted & $31.8 \pm 10.7$ \\
$\mathrm{FEV}_{1} / \mathrm{FVC}$, mean $\pm \mathrm{SD}$ & $0.4 \pm 0.1$ \\
$\mathrm{MRC}$ score, mean $\pm \mathrm{SD}$ arbitrary units & $2.6 \pm 0.9$ \\
$\mathrm{P}_{\text {Imax }}$, mean $\pm \mathrm{SD}$ cm $\mathrm{H}_{2} \mathrm{O}$ & $85 \pm 30.7$ \\
$\mathrm{P}_{\text {Imax }}$, mean $\pm \mathrm{SD} \%$ predicted & $81.9 \pm 26.3$ \\
$\mathrm{P}_{\text {Emax }}$, mean $\pm \mathrm{SD}$ cm $\mathrm{H}_{2} \mathrm{O}$ & $129.1 \pm 43.0$ \\
$\mathrm{P}_{\text {Emax }}$, mean $\pm \mathrm{SD} \%$ predicted & $92.3 \pm 31.5$ \\
& \\
\hline$N=17$ & \\
BMI $=$ body mass index & \\
MRC $=$ Medical Research Council dyspnea scale & \\
$\mathrm{P}_{\text {Imax }}=$ maximum inspiratory pressure & \\
$\mathrm{P}_{\text {Emax }}=$ maximum expiratory pressure & \\
\hline
\end{tabular}

with quiet breathing. From diaphragmatic breathing to diaphragmatic breathing plus pursed-lips breathing, a significant increase in expiratory time was associated with a significant decrease in the breathing frequency. With respect to the duty cycle, a significant decrease was observed during diaphragmatic breathing plus pursed-lips breathing when compared with quiet breathing and with diaphragmatic breathing.

The chest wall motion and asynchrony data during quiet breathing, diaphragmatic breathing, and diaphragmatic breathing plus pursed-lips breathing are presented in Table 3. The contribution of the abdominal compartment was $>50 \%$ on the 3 conditions. A significant increase in the percentage contribution of pulmonary rib cage was observed during diaphragmatic breathing plus pursed-lips breathing compared with quiet breathing. No other significant change was observed among the 3 conditions for any other chest wall contribution variable.

For the asynchrony variables, no significant differences were observed for the phase angle among the 3 conditions, whereas a significant increase was observed in the inspiratory phase ratio and expiratory phase ratio between all analyzed compartments during both diaphragmatic breathing and diaphragmatic breathing plus pursed-lips breathing compared with quiet breathing, without differences between the breathing exercises. During diaphragmatic breathing and diaphragmatic breathing plus pursed-lips breathing, the participants showed a significant increase in oxygen saturation compared with quiet breathing (quiet breathing, mean \pm SD $93.39 \% \pm 3.20 \%$; diaphragmatic breathing, $95.99 \% \pm 2.55 \%$; diaphragmatic breathing plus pursed-lips breathing, $95.96 \% \pm 2.61 \% ; P=.01$ ), with no significant difference between the breathing exercises. No significant changes were observed in heart rate for all 


\section{Diaphragmatic AND PURSED-LiPs BREATHing}

Table 2. Breathing Pattern Data at Quiet Breathing, Diaphragmatic Breathing, and Diaphragmatic Breathing Combined With Pursed-Lips Breathing

\begin{tabular}{|c|c|c|c|c|}
\hline Breathing Pattern & $\begin{array}{c}\text { Quiet } \\
\text { Breathing }\end{array}$ & $\begin{array}{l}\text { Diaphragmatic } \\
\text { Breathing }\end{array}$ & $\begin{array}{c}\text { Diaphragmatic Breathing } \\
\text { Combined With } \\
\text { Pursed-Lips Breathing }\end{array}$ & $P$ \\
\hline Chest wall volume, $\mathrm{L}$ & $0.5 \pm 0.1$ & $1.0 \pm 0.4^{*}$ & $1.1 \pm 0.4^{*}$ & $<.001$ \\
\hline End-inspiratory chest wall volume, $\mathrm{L}$ & $22.6 \pm 3.7$ & $23.2 \pm 3.8^{*}$ & $23.3 \pm 3.8^{*}$ & $<.001$ \\
\hline End-inspiratory rib-cage volume, $\mathrm{L}$ & $16.5 \pm 2.2$ & $16.8 \pm 2.3^{*}$ & $16.9 \pm 2.2^{*}$ & $<.001$ \\
\hline End-inspiratory abdomen volume, L & $6.1 \pm 1.7$ & $6.4 \pm 1.7^{*}$ & $6.5 \pm 1.7^{*}$ & $<.001$ \\
\hline End-expiratory chest wall volume, L & $22.1 \pm 3.6$ & $22.3 \pm 3.6$ & $22.3 \pm 3.6$ & .069 \\
\hline End-expiratory rib-cage volume, $\mathrm{L}$ & $16.3 \pm 2.2$ & $16.4 \pm 2.2$ & $16.4 \pm 2.2$ & .032 \\
\hline End-expiratory abdominal volume, $\mathrm{L}$ & $5.8 \pm 1.6$ & $5.8 \pm 1.6$ & $5.8 \pm 1.6$ & .67 \\
\hline$\dot{\mathrm{V}}_{\mathrm{E}}, \mathrm{L} / \mathrm{min}$ & $9.0 \pm 1.8$ & $10.1 \pm 3.3$ & $8.9 \pm 2.8$ & .09 \\
\hline Breathing frequency, breaths/min & $19.7 \pm 4.3$ & $11.8 \pm 4.9^{*}$ & $8.5 \pm 2.6^{* \dagger}$ & $<.001$ \\
\hline $\mathrm{T}_{\mathrm{I}}, \mathrm{s}$ & $1.3 \pm 0.3$ & $2.2 \pm 0.6^{*}$ & $2.4 \pm 0.7 *$ & $<.001$ \\
\hline $\mathrm{T}_{\mathrm{E}}, \mathrm{s}$ & $2.0 \pm 0.5$ & $3.7 \pm 1.2 *$ & $5.4 \pm 1.6^{* \dagger}$ & $<.001$ \\
\hline $\mathrm{T}_{\mathrm{I}} / \mathrm{T}_{\text {tot }}$ & $0.4 \pm 0.03$ & $0.4 \pm 0.1$ & $0.3 \pm 0.1 * \dagger$ & $<.001$ \\
\hline $\begin{array}{l}\text { Data are expressed as mean } \pm \text { SD. } \\
\text { * Significant difference vs quiet breathing. } \\
\dagger \text { Significant difference vs diaphragmatic breathing. } \\
\dot{\mathrm{V}}_{\mathrm{E}}=\text { minute ventilation } \\
\mathrm{T}_{\mathrm{I}}=\text { inspiratory time } \\
\mathrm{T}_{\mathrm{E}}=\text { expiratory time } \\
\mathrm{T}_{\mathrm{I}} / \mathrm{T}_{\text {tot }}=\text { duty cycle }\end{array}$ & & & & \\
\hline
\end{tabular}

Table 3. Chest Wall Motion and Asynchrony Data at Quiet Breathing, Diaphragmatic Breathing, and Diaphragmatic Breathing Combined With Pursed-Lips Breathing

\begin{tabular}{|c|c|c|c|c|}
\hline Variables & $\begin{array}{c}\text { Quiet } \\
\text { Breathing }\end{array}$ & $\begin{array}{c}\text { Diaphragmatic } \\
\text { Breathing }\end{array}$ & $\begin{array}{c}\text { Diaphragmatic } \\
\text { Breathing Combined } \\
\text { With Pursed-Lips } \\
\text { Breathing }\end{array}$ & $P$ \\
\hline \multicolumn{5}{|l|}{ Chest wall motion } \\
\hline Pulmonary rib-cage percentage contribution & $25.1 \pm 7.5$ & $26.5 \pm 5.8$ & $30.2 \pm 8.0^{*}$ & .01 \\
\hline Abdominal rib-cage percentage contribution & $13.7 \pm 4.4$ & $12.3 \pm 9.0$ & $12.2 \pm 10.8$ & .68 \\
\hline Abdomen percentage contribution & $61.3 \pm 10.7$ & $61.2 \pm 10.6$ & $57.6 \pm 14.1$ & .25 \\
\hline \multicolumn{5}{|l|}{ Asynchrony } \\
\hline Rib cage $\times$ abdomen, phase angle, degrees & $13.0 \pm 9.3$ & $19.0 \pm 10.4$ & $20.0 \pm 12.5$ & .11 \\
\hline Pulmonary rib cage $\times$ abdominal rib cage, phase angle, degrees & $10.4 \pm 8.1$ & $13.5 \pm 10.4$ & $16.1 \pm 9.3$ & .08 \\
\hline Inspiratory phase ratio rib cage $\times$ abdomen, $\%$ & $14.0 \pm 8.0$ & $30.3 \pm 16.4 *$ & $27.2 \pm 13.1^{*}$ & $<.001$ \\
\hline Inspiratory phase ratio pulmonary rib cage $\times$ abdominal rib cage, $\%$ & $12.5 \pm 5.1$ & $20.0 \pm 8.2 *$ & $20.3 \pm 8.7^{*}$ & $<.001$ \\
\hline Expiratory phase ratio rib cage $\times$ abdomen, $\%$ & $6.4 \pm 3.5$ & $18.1 \pm 10.6^{*}$ & $18.9 \pm 11.1^{*}$ & $<.001$ \\
\hline Expiratory phase ratio pulmonary rib cage $\times$ abdominal rib cage, $\%$ & $11.3 \pm 5.9$ & $22.2 \pm 9.5^{*}$ & $22.2 \pm 8.0^{*}$ & $<.001$ \\
\hline \multicolumn{5}{|l|}{$\begin{array}{l}\text { Data are expressed as mean } \pm \text { SD. } \\
* \text { Significant difference vs quiet breathing. } \\
\dagger \text { Significant difference vs diaphragmatic breathing. }\end{array}$} \\
\hline
\end{tabular}

comparisons (quiet breathing, mean \pm SD $74.69 \pm 14.37$ breaths/min; diaphragmatic breathing, $75.09 \pm 14.78$ breaths/min; diaphragmatic breathing plus pursed-lips breathing, $75.86 \pm 14.77$ breaths/min; $P=.67$ ). No significant differences were observed in dyspnea after the participants performed the breathing exercises in comparison with quiet breathing, as well as between them (quiet breathing, mean \pm SD $0.42 \pm 0.78$; diaphragmatic breath- ing, $0.57 \pm 0.96$; diaphragmatic breathing plus pursed-lips breathing, $0.52 \pm 0.79, P=.17)$.

\section{Discussion}

The main results of this study were the following: (1) the diaphragmatic breathing and the diaphragmatic breath- 
ing plus pursed-lips breathing resulted in significant increases in chest wall tidal volume compared with quiet breathing, (2) there was no difference in the abdominal contribution among the conditions (quiet breathing, diaphragmatic breathing, and diaphragmatic breathing plus pursed-lips breathing), (3) there was a significant increase in chest wall asynchrony during breathing exercises, (4) there was no significant change in dyspnea among the evaluated conditions, (5) significant decreases were observed in breathing frequency for both breathing exercises, and (6) diaphragmatic breathing plus pursed-lips breathing provided greater changes in breathing parameters, especially for time variables.

The increases in chest wall tidal volume during the breathing exercises were due to significant increases in end-inspiratory rib-cage volume and end-inspiratory abdomen volume, without changes in the end-expiratory chest wall volume. Other studies also reported significant increases in tidal volume during diaphragmatic breathing ${ }^{13,22,31}$ and during pursed-lips breathing ${ }^{14,17,23}$ when performed separately. The increase in tidal volume associated with the increase in the end-inspiratory chest wall volume indicated that the subjects were able to recruit the inspiratory reserve volume. The same result was observed in the study by Fernandes et $\mathrm{al}^{13}$ in a specific group of subjects with COPD $(65.5 \%$ of the sample) who also presented significant increases in tidal volume but no changes in end-expiratory volume. Those subjects were considered "responders" to the diaphragmatic breathing, were less hyperinflated, had greater inspiratory muscle strength, and presented more synchronous chest wall motion during diaphragmatic breathing. ${ }^{13}$

During pursed-lips breathing, the end-expiratory chest wall volume is important, once there is an increase in the expiratory time associated with the reduction of the breathing frequency that may contribute to the reduction of this volume, as reported by Bianchi et al. ${ }^{17}$ However, the effects of the pursed-lips breathing on end-expiratory chest wall volume are not consistent because studies demonstrated different effects, such as increases, decreases, or no changes, in this volume in subjects with COPD. ${ }^{14,23}$ In the present study, no statistical difference was observed for end-expiratory volumes, which might be related to a pattern of lower hyperinflation shown in the subjects ${ }^{14,32}$ and confirmed by increases in end-inspiratory chest wall volumes.

With regard to chest wall motion, although both breathing exercises duplicated the tidal volume in relation to quiet breathing, there was no increase in the contribution of the abdominal compartment. It is known that subjects with COPD have diminished diaphragmatic motion and a lower diaphragmatic excursion, ${ }^{33,34}$ and, depending on the severity of these alterations, this may interfere with the response to diaphragmatic breathing, ${ }^{13}$ which limits the involvement of the abdominal compartment. Moreover, our subjects already had a great contribution, of $61.26 \%$, of the abdomen while they were in the sitting position at quiet breathing (Table 2), similar to the findings of Priori et $\mathrm{al}^{35}$ who also observed a $60.51 \%$ abdominal contribution in male participants with COPD while in the sitting position at rest. Therefore, it is possible that there was a limitation in the response of the diaphragmatic breathing performed by these subjects. The inclusion of the pursed-lips breathing also did not alter the chest wall motion. In fact, some studies that assessed the effects of pursed-lips breathing showed a similar increase in the tidal volume in both the rib cage and the abdomen; however, the contribution of the compartments to the chest wall was not analyzed. ${ }^{14,17}$

Although there was a decrease in the breathing frequency and an increase in oxygen saturation during both breathing exercises, no significant differences were observed in dyspnea. The effectiveness of diaphragmatic breathing and pursed-lips breathing in relieving dyspnea varies greatly among subjects with COPD. With regard to diaphragmatic breathing, some studies report increases in dyspnea and suggest that the activity of the other respiratory muscles beyond the diaphragm and the chest wall asynchrony could be responsible. ${ }^{12,22,36}$ Breslin et al ${ }^{37}$ found an increase in the recruitment of inspiratory accessory muscles during pursed-lips breathing, which would be associated with the increase in dyspnea. However, Bianchi et al ${ }^{17}$ showed that, regardless of the level of pulmonary hyperinflation, the increase in the expiratory time and total time provided by pursed-lips breathing decreased dyspnea. The subjects in our study presented a low level of dyspnea during quiet breathing, according to the modified Borg scale score (quiet breathing, 0.42; diaphragmatic breathing, 0.56; diaphragmatic breathing plus pursed-lips breathing, 0.52).

With regard to the asynchrony, the present study showed no differences in phase angle among conditions, but significant increases in the inspiratory phase ratio and expiratory phase ratio were found during diaphragmatic breathing and diaphragmatic breathing plus pursed-lips breathing compared with quiet breathing. This finding corroborated reports of some studies of subjects with COPD that found increases in asynchrony during diaphragmatic breathing, $10,13,29,30$ which seem to be related to (1) the sitting position assumed for the evaluation (a higher trunk elevation favors greater asynchrony in subjects with COPD), ${ }^{29}$ (2) the voluntary changes in the breathing pattern assumed during the breathing exercises (even for healthy subjects, the spontaneous breathing pattern presents asynchrony), ${ }^{38}$ and (3) the greater focus on the use of the diaphragm (according to the instructions for diaphragmatic breathing and diaphragmatic breathing plus pursed-lips breath- 
ing) performed by subjects with biomechanical impairment of this muscle when considering that they have a respiratory overload while performing any type of exercise. ${ }^{30,39}$

Both breathing exercises promoted a decrease in the breathing frequency due to the increase of inspiratory time and expiratory time. Those changes in breathing pattern supported the findings of previous studies of the effects of diaphragmatic breathing and pursed-lips breathing assessed separately. ${ }^{13,14,17,22,40,41}$ It is noteworthy that diaphragmatic breathing plus pursed-lips breathing compared with diaphragmatic breathing resulted in a lower breathing frequency once it promoted greater expiratory time. This finding agreed with the conclusions of Jones et $\mathrm{al}^{5}$ who evaluated the effects of diaphragmatic breathing and diaphragmatic breathing plus pursed-lips breathing in 30 subjects with COPD. The investigators also found a greater decrease in the breathing frequency when diaphragmatic breathing and pursed-lips breathing were combined compared with quiet breathing and with diaphragmatic breathing separately. The decrease in expiratory flow leads to a lower drop in the pressure along the airways, which prevents the collapse of the airways and, therefore, reduces air trapping. Thus, it is suggested that subjects with minor lung elastic recoil pressure would benefit the most from this technique. ${ }^{6,10,42}$ Concomitantly, diaphragmatic breathing plus pursed-lips breathing promoted a significant decrease in duty cycle and led to an increased time for lung emptying. ${ }^{10,37}$

Jones et $\mathrm{al}^{5}$ also evaluated oxygen consumption during spontaneous breathing at rest and during breathing exercises (diaphragmatic breathing and diaphragmatic breathing plus pursed-lips) and found no changes in this variable among the 3 conditions. However, this variable was not assessed in our study, which limits comparisons. Moreover, dynamic hyperinflation and diaphragmatic mobility were not directly analyzed, which limits a possible distinction among subjects who may have responded differently to the breathing exercises. Future studies should include these parameters in the analysis of the effects of combined breathing exercises to determine subjects who may receive the most clinical benefit.

This study supported the positive acute effects of diaphragmatic breathing and the diaphragmatic breathing plus pursed-lips breathing exercises for individuals with COPD. Moreover, it adds to the knowledge base regarding the effects of the combination of the exercises that had been previously assessed only for the outcomes of breathing frequency and oxygen consumption. The addition of pursed-lips breathing to diaphragmatic breathing provided greater changes in breathing parameters, especially for time variables.
In addition, the results of this study have important clinical implications for symptom management in individuals with COPD. The assessed breathing exercises were demonstrated to improve chest wall volumes and oxygenation, and to reduce breathing frequency without increasing dyspnea. Therefore, these exercises might be helpful for individuals who feel anxious and tense when it is difficult to breathe, as well as for individuals trying to manage sudden COPD symptoms. The exercises may play a role in care and symptom management, and thus may be taught in pulmonary rehabilitation and nursing care programs, and be included in routine care of individuals with COPD.

Despite the benefits described regarding breathing exercises, this study had some limitations. One was a mismatch between the number of men and women in the sample. When considering that it was a nonprobabilistic sample, the first subjects who showed interest in participating in the study were included, and those were mainly men. Therefore, it was not possible to control for sex disparity. In addition, this study evaluated the effects of breathing exercises at rest. We can wonder whether the benefits of breathing exercise, such as improved oxygenation and chest wall volumes, would be more favorable, for example, during exercise performance because that is when dyspnea symptoms appear.

\section{Conclusions}

Our results showed that diaphragmatic breathing and diaphragmatic breathing plus pursed-lips breathing improved chest wall volumes and oxygenation as well as reduced the breathing frequency, which provided more volume for hematosis without increasing dyspnea. The addition of pursed-lips breathing to diaphragmatic breathing provided greater changes in breathing parameters, especially in relation to time variables. Therefore, this study supported the positive acute effects of these breathing exercises for subjects with COPD. These breathing exercises are low cost and do not require special instrumentation or continuous assistance of a health care provider, which can improve adherence of the patients to their routine.

\section{REFERENCES}

1. Vogelmeier CF, Criner GJ, Martinez FJ, Anzueto A, Barnes PJ, Bourbeau J, et al. Global Strategy for the Diagnosis, Management, and Prevention of Chronic Obstructive Lung Disease 2017 Report GOLD Executive Summary Am J Respir Crit Care Med 2017;195(5): 557-582.

2. Moore E, Palmer T, Newson R, Majeed A, Quint JK, Soljak MA. Pulmonary Rehabilitation as a Mechanism to Reduce Hospitalizations for Acute Exacerbations of COPD: A Systematic Review and Meta-Analysis. Chest 2016;150(4):837-859. 


\section{Diaphragmatic and PuRsed-Lips Breathing}

3. Spruit MA, Singh SJ, Garvey C, ZuWallack R, Nici L, Rochester C, et al; ATS/ERS Task Force on Pulmonary Rehabilitation. An official American Thoracic Society/European Respiratory Society statement: key concepts and advances in pulmonary rehabilitation. Am J Respir Crit Care Med 2013;188(8):e13-e64.

4. McCarthy B, Casey D, Devane D, Murphy K, Murphy E, Lacasse Y. Pulmonary rehabilitation for chronic obstructive pulmonary disease. Cochrane Database Syst Rev 2015;(2):CD003793.

5. Jones AY, Dean E, Chow CC. Comparison of the oxygen cost of breathing exercises and spontaneous breathing in patients with stable chronic obstructive pulmonary disease. Phys Ther 2003; 83(5):424-431.

6. Dechman G, Wilson CR. Evidence underlying breathing retraining in people with stable chronic obstructive pulmonary disease. Phys Ther 2004;84(12):1189-1197.

7. Holland AE, Hill CJ, Jones AY, McDonald CF. Breathing exercises for chronic obstructive pulmonary disease. Cochrane Database Syst Rev 2012;10:CD008250.

8. Seo K, Hwan PS, Park K. The effects of inspiratory diaphragm breathing exercise and expiratory pursed-lip breathing exercise on chronic stroke patients' respiratory muscle activation. J Phys Ther Sci 2017;29(3):465-469.

9. Karam M, Kaur BP, Baptist AP. A modified breathing exercise program for asthma is easy to perform and effective. J Asthma 2017;54(2):217-222.

10. Gosselink R. Breathing techniques in patients with chronic obstructive pulmonary disease (COPD). Chron Respir Dis 2004; 1(3):163-172.

11. Borge CR, Hagen KB, Mengshoel AM, Omenaas E, Moum T, Wahl AK. Effects of controlled breathing exercises and respiratory muscle training in people with chronic obstructive pulmonary disease: results from evaluating the quality of evidence in systematic reviews. BMC Pulm Med 2014;14:184.

12. Cahalin LP, Braga M, Matsuo Y, Hernandez ED. Efficacy of diaphragmatic breathing in persons with chronic obstructive pulmonary disease: a review of the literature. J Cardiopulm Rehabil 2002;22(1): 7-21.

13. Fernandes M, Cukier A, Feltrim MI. Efficacy of diaphragmatic breathing in patients with chronic obstructive pulmonary disease. Chron Respir Dis 2011;8(4):237-244.

14. Bianchi R, Gigliotti F, Romagnoli I, Lanini B, Castellani C, Binazzi $\mathrm{B}$, et al. Patterns of chest wall kinematics during volitional pursedlip breathing in COPD at rest. Respir Med 2007;101(7):14121418.

15. Visser FJ, Ramlal S, Dekhuijzen PN, Heijdra YF. Pursed-lips breathing improves inspiratory capacity in chronic obstructive pulmonary disease. Respiration 2011;81(5):372-378.

16. Mayer AF, Karloh M, Dos Santos K, de Araujo CLP, Gulart AA. Effects of acute use of pursed-lips breathing during exercise in patients with COPD: a systematic review and meta-analysis. Physiotherapy 2018;104(1):9-17.

17. Bianchi R, Gigliotti F, Romagnoli I, Lanini B, Castellani C, Grazzini M, Scano G. Chest wall kinematics and breathlessness during pursed-lip breathing in patients with COPD. Chest 2004; $125(2): 459-465$.

18. World Health Organization. Global Database on Body Mass Index. 2014. http://www.who.int/bmi/index.jsp. Accessed March 7, 2016.

19. Kovelis D, Segretti NO, Probst VS, Lareau SC, Brunetto AF, Pitta F. Validation of the Modified Pulmonary Functional Status and Dyspnea Questionnaire and the Medical Research Council scale for use in Brazilian patients with chronic obstructive pulmonary disease. J Bras Pneumol 2008;34(12):1008-1018.
20. Neder JA, Andreoni S, Lerario MC, Nery LE. Reference values for lung function tests. II. Maximal respiratory pressures and voluntary ventilation. Braz J Med Biol Res 1999;32(6):719-727.

21. Miller MR, Hankinson J, Brusasco V, Burgos F, Casaburi R, Coates A, et al; ATS/ERS Task Force. Standardisation of spirometry. Eur Respir J 2005;26(2):319-338.

22. Vitacca M, Clini E, Bianchi L, Ambrosino N. Acute effects of deep diaphragmatic breathing in COPD patients with chronic respiratory insufficiency. Eur Respir J 1998;11(2):408-415.

23. Spahija J, de Marchie M, Grassino A. Effects of imposed pursed-lips breathing on respiratory mechanics and dyspnea at rest and during exercise in COPD. Chest 2005;128(2):640-650.

24. Mayer OH, Clayton RG Sr, Jawad AF, McDonough JM, Allen JL. Respiratory inductance plethysmography in healthy 3- to 5-year-old children. Chest 2003;124(5):1812-1819.

25. Vieira DS, Hoffman M, Pereira DA, Britto RR, Parreira VF. Optoelectronic plethysmography: intra-rater and inter-rater reliability in healthy subjects. Respir Physiol Neurobiol 2013;189(3): 473-476.

26. Cala SJ, Kenyon CM, Ferrigno G, Carnevali P, Aliverti A, Pedotti A, et al. Chest wall and lung volume estimation by optical reflectance motion analysis. J Appl Physiol 1996;81(6):2680-2689.

27. Parreira VF, Vieira DS, Myrrha MA, Pessoa IM, Lage SM, Britto RR. Optoelectronic plethysmography: a review of the literature. Rev Braz Fisioter 2012;16(6):439-453.

28. Johnson MJ, Close L, Gillon SC, Molassiotis A, Lee PH, Farquhar MC, Breathlessness Research Interest Group (BRIG). Use of the modified Borg scale and numerical rating scale to measure chronic breathlessness: a pooled data analysis. Eur Respir J 2016;47(6):18611864.

29. Sackner MA, Gonzalez H, Rodriguez M, Belsito A, Sackner DR, Grenvik S. Assessment of asynchronous and paradoxic motion between rib cage and abdomen in normal subjects and in patients with chronic obstructive pulmonary disease. Am Rev Respir Dis 1984; 130(4):588-593.

30. Cancelliero-Gaiad KM, Ike D, Pantoni CB, Borghi-Silva A, Costa D. Respiratory pattern of diaphragmatic breathing and pilates breathing in COPD subjects. Braz J Phys Ther 2014;18(4):291-299.

31. Sackner MA, Gonzalez HF, Jenouri G, Rodriguez M. Effects of abdominal and thoracic breathing on breathing pattern components in normal subjects and in patients with chronic obstructive pulmonary disease. Am Rev Respir Dis 1984;130(4):584-587.

32. Aliverti A. Lung and chest wall mechanics during exercise: effects of expiratory flow limitation. Respir Physiol Neurobiol 2008;163(1-3): 90-99.

33. Paulin E, Yamaguti WP, Chammas MC, Shibao S, Stelmach R, Cukier A, Carvalho CR. Influence of diaphragmatic mobility on exercise tolerance and dyspnea in patients with COPD. Respir Med 2007;101(10):2113-2118.

34. Dos Santos Yamaguti WP, Paulin E, Shibao S, Chammas MC, Salge JM, Ribeiro M, et al. Air trapping: The major factor limiting diaphragm mobility in chronic obstructive pulmonary disease patients. Respirology 2008;13(1):138-144.

35. Priori R, Aliverti A, Albuquerque AL, Quaranta M, Albert P, Calverley PM. The effect of posture on asynchronous chest wall movement in COPD. J Appl Physiol 2013;114(8):1066-1075.

36. Gosselink RA, Wagenaar RC, Rijswijk H, Sargeant AJ, Decramer ML. Diaphragmatic breathing reduces efficiency of breathing in patients with chronic obstructive pulmonary disease. Am J Respir Crit Care Med 1995;151(4):1136-1142.

37. Breslin EH. The pattern of respiratory muscle recruitment during pursed-lip breathing. Chest 1992;101(1):75-78. 


\section{Diaphragmatic and PuRsed-Lips Breathing}

38. Vieira DS, Mendes LP, Elmiro NS, Velloso M, Britto RR, Parreira VF. Breathing exercises: influence on breathing patterns and thoracoabdominal motion in healthy subjects. Braz J Phys Ther 2014;18(6):544-552.

39. França DC, Vieira DSR, Vieira BdSPP, Oliveira TGe, Britto RR, Parreira VF. Lower-limb endurance training program influences thoracoabdominal motion of patients with COPD? Fisioter Mov 2013;26(1):141-150.

40. Garrod R, Dallimore K, Cook J, Davies V, Quade K. An evaluation of the acute impact of pursed lips breathing on walking distance in nonspontaneous pursed lips breathing chronic obstructive pulmonary disease patients. Chron Respir Dis 2005;2(2):67-72.

41. Faager G, Stâhle A, Larsen FF. Influence of spontaneous pursed lips breathing on walking endurance and oxygen saturation in patients with moderate to severe chronic obstructive pulmonary disease. Clin Rehabil 2008;22(8):675-683

42. Ingram RH Jr, Schilder DP. Effect of pursed lips expiration on the pulmonary pressure-flow relationship in obstructive lung disease. Am Rev Respir Dis 1967;96(3):381-388.

This article is approved for Continuing Respiratory Care Education credit. For information and to obtain your CRCE

(free to AARC members) visit www.rcjournal.com 